\title{
Synthesis, characteristics, and photocatalytic activity of zinc oxide nanoparticles stabilized on the stone surface for degradation of metronidazole from aqueous solution
}

\author{
Amir Nasser Alibeigi ${ }^{1 \mathbb{D}}$, Neda Javid ${ }^{2,3}{ }^{\mathbb{D}}$, Majid Amiri Gharaghani $^{1^{+}}{ }^{\mathbb{D}}$, Zhila Honarmandrad $^{2,4^{*}}{ }^{\mathbb{D}}$ Fatemeh Parsaie $^{5}$ \\ ${ }^{1}$ Department of Environmental Health Engineering, Sirjan School of Medical Sciences, Sirjan, Iran \\ ${ }^{2}$ Environmental Health Engineering Research Center, Kerman University of Medical Sciences, Kerman, Iran \\ ${ }^{3}$ Department of Environmental Health Engineering, Zarand School of Nursing, Kerman University of Medical Sciences, Kerman, Iran \\ ${ }^{4}$ Department of Process Engineering and Chemical Technology, Faculty of Chemistry, Gdansk University of Technology, 80-233 \\ Gdańsk, 11/12 Narutowicza Str, Poland
}

${ }^{5}$ Student Research Committee, Sirjan School of Medical Sciences, Sirjan, Iran

\begin{abstract}
Background: The presence of antibiotics such as metronidazole in wastewater even at low concentrations requires searching for a suitable process such as advanced oxidation process (AOP) to reduce the level of pollutants to a standard level in water.

Methods: In this study, zinc oxide $(\mathrm{ZnO})$ nanoparticles were synthesized by thermal method using zinc sulfate $\left(\mathrm{ZnSO}_{4}\right)$ as a precursor, then, stabilized on stone and was used as a catalyst, in order to degrade metronidazole by photocalytic process. Effective factors on the removal efficiency of metronidazole including the initial metronidazole concentration, contact time, $\mathrm{pH}$, and $0.9 \mathrm{gL}^{-1} \mathrm{ZnO}$ stabilized on the stone surface were investigated.

Results: The X-ray diffraction (XRD) studies showed that the synthesized nanomaterials have hexagonal Wurtzite structure. Also, scanning electron microscopy (SEM) analysis revealed that the average crystalline size of the synthesized $\mathrm{ZnO}$ particles was in the range of 1.9-3.2 $\mathrm{nm}$. The spectra represented a sharp absorption edge at $390 \mathrm{~nm}$ for $\mathrm{ZnO}$ nanoparticles corresponding to band gap of $3.168 \mathrm{eV}$. The BET-BJH specific surface area of the synthesized $\mathrm{ZnO}$ nanoparticles was $25.504 \mathrm{~m}^{2} / \mathrm{g}$. The EDS spectrum of $\mathrm{ZnO}$ nanoparticles showed four peaks, which were identified as $\mathrm{Zn}$ and $\mathrm{O}$. The maximum removal efficiency was $98.36 \%$ for the synthetic solution under a specific condition $(\mathrm{pH}=11$, reaction time $=90$ minutes, $\mathrm{ZnO}$ concentration $=0.9 \mathrm{gL}^{-1}$, and the initial concentration of metronidazole $=10$ $\left.\mathrm{mgL}^{-1}\right)$. The photocatalytic degradation was found to follow pseudo-first-order degradation kinetics.

Conclusion: Therefore, the $\mathrm{ZnO}$ nanoparticles synthesized by thermal decomposition are suitable and effective photocatalytic materials for degradation of pharmaceutical contaminants.

Keywords: Zinc oxide, Metronidazole, Ultraviolet rays, Nanoparticles

Citation: Alibeigi AN, Javid N, Amiri Gharaghani M, Honarmandrad Z, Parsaie F. Synthesis, characteristics, and photocatalytic activity of zinc oxide nanoparticles stabilized on the stone surface for degradation of metronidazole from aqueous solution. Environmental Health Engineering and Management Journal 2021; 8(1): 55-63. doi: 10.34172/EHEM.2021.08.
\end{abstract}

\section{Article History:}

Received: 11 December 2020 Accepted: 15 February 2021 ePublished: 9 March 2021

\section{Introduction}

Antibiotics are widely introduced into water and the environment through domestic wastewater, pharmaceutical wastewater, hospital wastewater, and veterinary clinics (1-3). Metronidazole $\left(\mathrm{C}_{6} \mathrm{H}_{9} \mathrm{~N}_{3} \mathrm{O}_{3}\right)$ belongs to nitroimidazole antibiotics. Metronidazole is widely used in the treatment of diseases caused by grampositive and gram-negative bacteria (4). The first cycle of entry of these antibiotics into the environment is through human consumption and its entry into wastewater and there is enough evidence of its presence in wastewater $(5,6)$. Persistent consumption of this antibiotic leads to the biological resistance of human body against diseases caused by gram-positive and gram-negative bacteria. The existence of these pharmaceuticals in wastewater is considered as emerging contaminants (7). Thus, it is necessary to remove these pharmaceuticals from aqueous solutions before their discharge into the environmental cycle $(7,8)$. Different processes including ion exchange, reverse osmosis, adsorption, biological treatment, and advanced oxidation such as photocatalytic process can be applied (8-10). Photocatalytic oxidation as one of the advanced oxidation processes (AOPs) due to strong decomposition characteristic of hydroxyl radicals in 
removal of organic pollutant has attracted much attention (Eq. 1-10). Various catalysts can be used in photocatalytic process $(9,11-13)$.

Catalyst $+\mathrm{hv} \rightarrow \mathrm{e}^{-}+\mathrm{h}^{+}(1)$

$\mathrm{e}^{-}+\mathrm{h}^{+} \rightarrow$ heat (2)

$\mathrm{h}^{+}+\mathrm{H}_{2} \mathrm{O} \rightarrow \mathrm{OH}^{\circ}+\mathrm{H}^{+}(3)$

$\mathrm{h}^{+}+\mathrm{OH}^{-} \rightarrow \mathrm{OH}^{\circ}(4)$

$\mathrm{h}^{+}+$Organic Matter $\rightarrow$ Oxidation Organic Matte (5)

$\mathrm{e}^{-}+\mathrm{O}_{2} \rightarrow \mathrm{O}_{2}^{-^{\circ}}(6)$

$\mathrm{O}_{2}^{-^{\circ}}+\mathrm{HO}_{2}^{\circ}+\mathrm{H}^{+} \rightarrow \mathrm{H}_{2} \mathrm{O}_{2}+\mathrm{O}_{2}(7)$

$\mathrm{O}_{2}^{-{ }^{\circ}}+$ Organic Matter $\rightarrow$ Organic Matter ${ }^{\circ}+(8)$

$\mathrm{OH}^{\circ}+$ Organic Matter $\rightarrow$ Int. $\rightarrow$ Organic Matter ${ }^{\circ}+(9)$

Nanoparticles because of their specific physical and chemical properties have attracted the attention of many scientists. The materials in Nano size have a considerable different behavior in volumetric measurement (14). Nanoparticles with a size of 1-100 nm with infinitesimal size and a very high surface area have been widely utilized. Because of the electrical, optical, chemical, and magnetic properties of metal nanoparticles, they are used in medical and industries widely (12). Some metal nanoparticles such as $\mathrm{Fe}_{2} \mathrm{O}_{3}, \mathrm{ZrO}_{2}, \mathrm{Cds}, \mathrm{TiO}_{2}$, zinc oxide $(\mathrm{ZnO})$, and $\mathrm{SnO}_{2}$ are used in industry and studies, among which $\mathrm{ZnO}$ and $\mathrm{TiO}_{2}$ are very important $(15,16)$. These nanoparticles are used in industry, wastewater treatment, fungicide, and bactericide. The Zno nanoparticle has extensive applications in system and processes of biosensors, gaseous sensors, solar cells, ceramics, nano generators, photo detectors, catalyzers, ultraviolet (UV) adsorbents in cosmetic and veneer of antivirus, pigments, optical materials, photocatalyst, electrical and optical processes $(17,18)$. In the last two decades, photocatalysts using semiconductor materials such as $\mathrm{ZnO}$ have attracted special attention due to their high optical sensitivity, high stability wide band gap and high efficiency in electron production. Using these nanoparticles, the energy Gap's property can adsorb a wide range of UV (19-21). Because of the extensiveness of nanoparticles and their applications, different methods are used for their production, the choice of which depends on the kind of materials and their application $(22,23)$. There are many different methods for the production of nanoparticles such as sol-gel, spray, pyrolysis spray, thermal decomposition, thermal vapor, microemulsion, hydrothermal and chemical processes (14). Differences in the process of these methods can cause a change in the structure, morphology, size, and physical behavior of nanoparticles. Thermal decomposition is one of the most important methods in the synthesis of nanoparticles. This process is easily controllable. Furthermore, different particle sizes are obtained in thermal decomposition. Through the experiment and with change of different factors such as temperature, $\mathrm{pH}$, and time, favorable production with a special size can be achieved (24). Also, using this process, most pure production can be achieved. The aim of this study was to investigate photocatalytic decomposition of metronidazole through
$\mathrm{ZnO}$ nanoparticles synthesized by thermal method and stabilization on stone media.

\section{Materials and Methods \\ Materials}

Metronidazole (99\% purity, Pars Darou Pharmaceutical), $\mathrm{ZnSO}_{4}$ (99.5\% purity, Merck), $\mathrm{Na}_{2} \mathrm{CO}_{3}$ (99.9\% purity, Merck), and ethanol (99.93\% purity, Merck) were purchased. The solution $\mathrm{pH}$ was calibrated by $\mathrm{NaOH}$ and $0.1 \mathrm{M} \mathrm{HCl}$.

Preparation and characterization of $\mathrm{ZnO}$ nanoparticles Using thermal method, nanoparticles were synthesized. Zinc sulfate solution $\left(\mathrm{ZnSO}_{4} \cdot 7 \mathrm{H}_{2} \mathrm{O}\right)$ with an amount of $0.5 \mathrm{M}$ was supplied in double distilled water. In the next step, the solution of sodium carbonate $(0.4 \mathrm{M})$ was added to the zinc sulfate solution drop by drop with an agitator for 45 minutes at $70^{\circ} \mathrm{C}$, as long as $\mathrm{Zn}_{4}\left(\mathrm{SO}_{4}\right)(\mathrm{OH})_{6} \cdot 0.5 \mathrm{H}_{2} \mathrm{O}$ formed. Then, white deposit was gathered by filtration and washed several times with ethanol and distilled water. Afterwards, in order to dry it, it was put in an oven at $70^{\circ} \mathrm{C}$. In the last stage, the precursors were calcined at $825^{\circ} \mathrm{C}$ for 1 hour, as shown in Figure $1(25,26)$.

Degradation of metronidazole was investigated by a UV-Vis spectrophotometer (Shimadzu, Japan). Fouriertransform infrared (FT-IR) spectra were measured with a JASCO spectra-meter 4100. For crystallographic structural analysis, X-ray diffraction (XRD) measurement was conducted using an X-ray diffract meter (GNR, MP 3000 , Italy) at $30 \mathrm{~mA}$ and $40 \mathrm{kV}$, which involved the usage of $\mathrm{Cu} \mathrm{K}_{\alpha}$ radiation, $\left(\lambda=0.154056 \mathrm{~A}^{\circ}\right)$ for $2 \Theta$ between $4.033^{\circ}$ and $69.969^{\circ}$. Transmission electron micrographs (TEMs) were obtained using a microscope (Philips CM30, Netherland), which operates at an accelerating voltage of $120 \mathrm{kV}$. Scanning electron microscopy (SEM) was performed to detect the morphology of the $\mathrm{ZnO}$ nanoparticles (Vega TESCAN, Czech Republic). A spectrophotometer (Varian Cary eclipse, USA) was used to record the photoluminescence spectra (PL) induced with a wavelength of $325 \mathrm{~nm}$. The band gap of $\mathrm{ZnO}$ nanoparticles synthesized was determined by a UV-Visible spectrum of nanoparticles using a double-beam UV-Vis spectrophotometer (Shimadzu UV-2550, Japan). SEM was used to observe the morphology of $\mathrm{ZnO}$ nanoparticles.

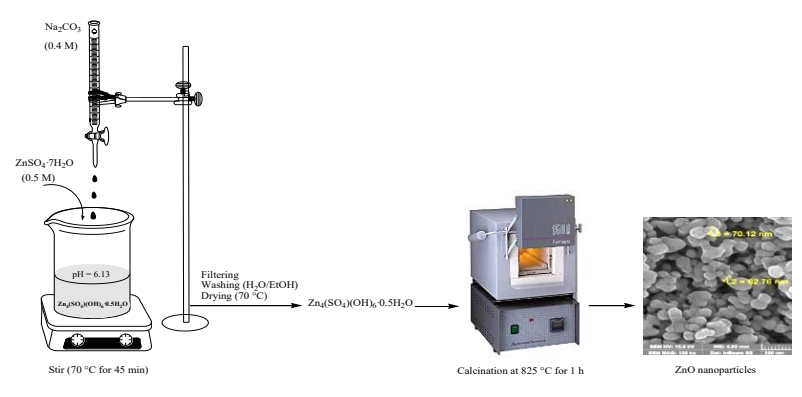

Figure 1. Experimental procedure for synthesis of $\mathrm{ZnO}$ nanoparticles. 
The chemical composition and stoichiometry of the $\mathrm{ZnO}$ films were analyzed by the EDS, which was equipped with a scanning electron microscope (JSM-5600 V, JEOL, Singapore).

\section{Photocatalytic activity}

The photocatalytic activity of the prepared $\mathrm{ZnO}$ nanoparticles was evaluated for degradation of $10,15,20$, and $25 \mathrm{mgL}^{-1}$ metronidazole solution and $0.9 \mathrm{gL}^{-1} \mathrm{ZnO}$ nanoparticles at different reaction times of $15,30,45,60$, 75 , and 90 minutes. The $\mathrm{pH}$ of both solutions was adjusted to 3,7 , and 11 at laboratory temperature $\left(25^{\circ} \mathrm{C}\right)$. The suspension was stirred continuously for 30 minutes in dark before irradiation to achieve the equilibrium absorption of $\mathrm{ZnO}$ with metronidazole solution. At each 5-minute interval, $10 \mathrm{~mL}$ metronidazole solution was collected and centrifuged at $5000 \mathrm{rpm}$ for 5 minutes and filtered by a Whatman cellulose acetate membrane filter with a pore size of 0.45 micron. Metronidazole concentration residual in the solution was measured using a UV/Visible spectrophotometer at the maximum wavelength of 320 $\mathrm{nm}$. At the end, the removal efficiency of metronidazole was calculated using Eq. (10).

$\% R=\left[\left(C_{0}-C_{t}\right) / C_{0}\right] \times 100(10)$

Where $C_{0}$ is the initial concentrations of metronidazole and $C_{t}$ is the concentration of metronidazole at time $t$.

Metronidazole removal efficiency was evaluated in a real sample. The real sample was obtained from wastewater treatment plant sewage of Kerman. The characteristics of municipal wastewater are shown in Table 1.

Photocatalytic removal of metronidazole in the aqueous solution using prepared $\mathrm{ZnO}$ nanoparticles was performed in a 300-mL plexiglass tubular photoreactor with three UV-C lamps ( $6 \mathrm{~W}, \lambda \max =245 \mathrm{~nm}$, Philips, the Netherlands), which was placed above the surface of stone plate. Eventually, the reactor was mixed with a peristaltic pump in order to keep the solution homogeneous. The kinetics of the photocatalytic degradation of metronidazole solutions were evaluated by measuring the changes in the emission spectra at different time intervals. The graph was plotted between $\ln C_{0} / C_{t}$ against time (t) (Eq. 11). If the $\ln \mathrm{C}_{0} / \mathrm{C}_{\mathrm{t}}$ graph versus reaction time is a straight line, the graph slope indicates the rate constant $(\mathrm{k})(12,27,28)$. From the slope of the graph, the rate of the photocatalytic degradation of metronidazole was determined (27,29-31).

Table 1. Parameters of kinetic models

\begin{tabular}{lccc}
\hline $\mathbf{C}_{\mathbf{0}}$ : Metronidazole $\left(\mathrm{mgL}^{-1}\right)$ & $\mathbf{R}^{\mathbf{2}}$ & $\mathbf{K}_{\text {obs }}(\mathbf{1} / \mathrm{min})$ & Line Equation \\
\hline 10 & 0.98 & 0.027 & $\mathrm{Y}=0.0297 \mathrm{x}+0.0258$ \\
\hline 15 & 0.97 & 0.022 & $\mathrm{Y}=0.0221 \mathrm{x}+0.0357$ \\
\hline 20 & 0.99 & 0.015 & $\mathrm{Y}=0.015 \mathrm{x}+0.1216$ \\
\hline 25 & 0.96 & 0.014 & $\mathrm{Y}=0.014 \mathrm{x}+0.08$ \\
\hline
\end{tabular}

According to Eq. (12), the Langmuir-Hinshelwood (L$\mathrm{H})$ model can be used for calculating the photocatalyst's kinetics reaction of some organic pollutants.

$$
\begin{aligned}
& r=\frac{d c}{d t} \times \frac{\operatorname{Kr} \operatorname{Kad} C}{1+\operatorname{Kad} C}(11) \\
& \ln \left(\mathrm{C} / \mathrm{C}_{0}\right)=\operatorname{Kt}(12)
\end{aligned}
$$

Where $C$ is the concentration of metronidazole at time $t$ (mg/L), $K_{a d}$ is the absorption equilibrium constant, and $K_{r}$ is reaction rate constant.

Eq. (12) can be simplified to express the pseudo-firstorder kinetics with a known rate constant $(\mathrm{K})(16,17,32)$.

\section{Results}

Figure 2 shows the XRD patterns of $\mathrm{ZnO}$ samples. The results confirmed that the diffraction patterns are almost identical and there are no additional peaks related to other elements, indicating no changes in the crystalline structure. The sharpness of the peaks indicates the crystalline structure of the nanoparticles. The average size of $\mathrm{ZnO}$ nanoparticles was obtained to be $54 \mathrm{~nm}$, which was calculated using Scherrer's formula (Eq. 13).

$\mathrm{D}=\mathrm{k} \lambda / \mathrm{b} \operatorname{Cos} \Theta \max (13)$

Where " $D, \lambda, b, k$, and $\theta$ " are the average crystal size, the radiation wavelength, the full width at half-maximum (FWHM), Scherrer constant (equal to 0.94 for FWHM of spherical crystals with cubic symmetry), and the diffraction angle of the peak, respectively.

The spectral absorption edge was located around 390 $\mathrm{nm}$ and the average size of nanoparticles was calculated based on the Henglein's empirical relationship between particle size and absorption start $(\lambda)$ (Eq. 14).

$2 \mathrm{R}=0.1 /(0.138-0: 0002345 \lambda) \mathrm{nm}(14)$

Where $2 R$ is the particle diameter. The average diameter of nanoparticles was estimated to be $2.148 \mathrm{~nm}$ (12).

The surface morphology of the synthesized $\mathrm{ZnO}$ nanoparticles was investigated by the SEM images. The results are shown in Figure 3, which obviously demonstrates the configuration of $\mathrm{ZnO}$ nanoparticles. The average particles size of the $\mathrm{ZnO}$ nanoparticles is in the range of $20-30 \mathrm{~nm}$ and the particles shape is almost spherical. Also, the particles were found in a size less than $100 \mathrm{~nm}$.

The transmission electron microscopy (TEM) images of the as-prepared $\mathrm{ZnO}$ nanoparticles are shown in Figure 4. These images show that the size of synthesized $\mathrm{ZnO}$ nanoparticle is very consistent and less agglomeration was observed between $\mathrm{ZnO}$ nanoparticles.

The EDS analysis was used to confirm the chemical composition and purity of the synthesized $\mathrm{ZnO}$ nanoparticles. The results are shown in Figure 5. As 


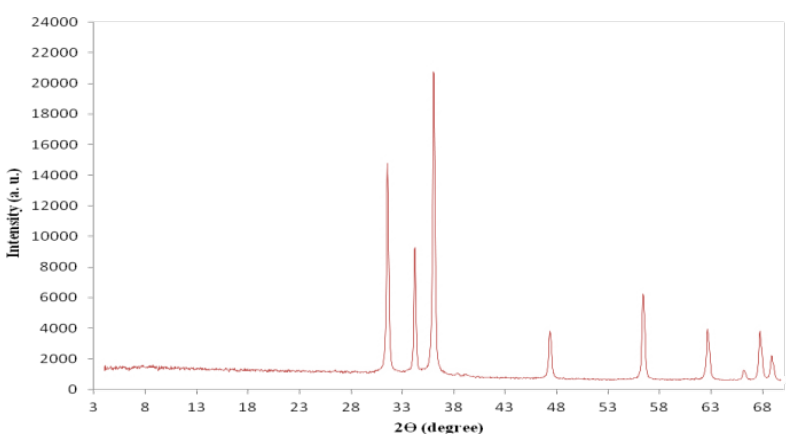

Figure 2. The XRD pattern of the stabilized $\mathrm{ZnO}$ nanoparticles on the stone surface.

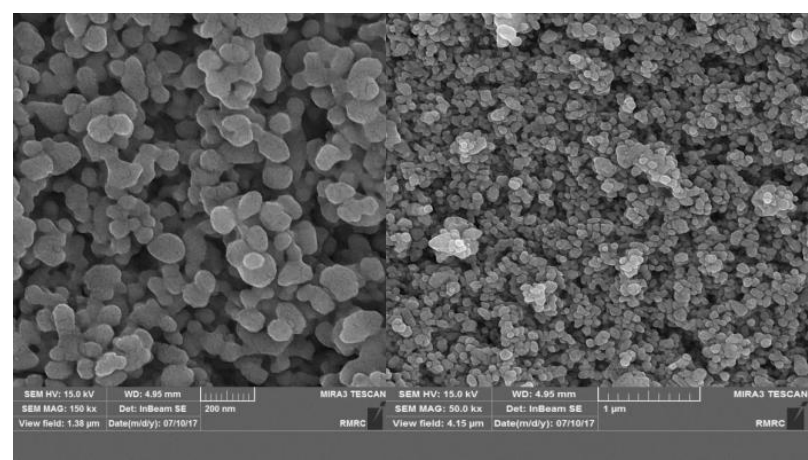

Figure 3. SEM images of the stabilized $\mathrm{ZnO}$ nanoparticles on the stone surface.

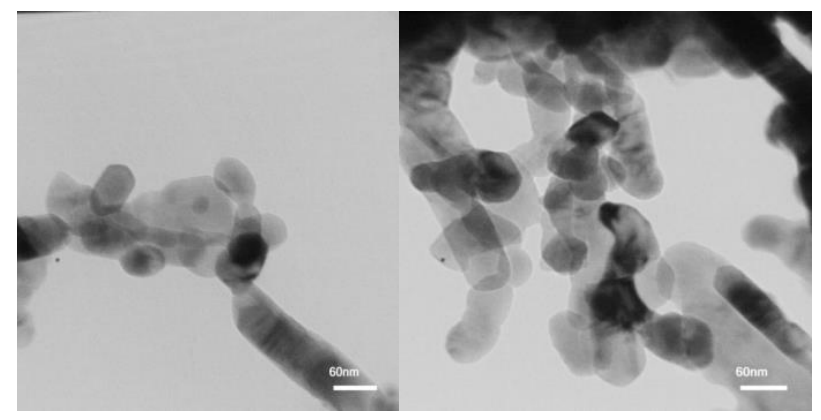

Figure 4. TEM images of as-prepared $\mathrm{ZnO}$ nanoparticles.

shown in this figure, only the elements $\mathrm{Zn}$ and $\mathrm{O}$ are present in $\mathrm{ZnO}$ nanoparticles, which confirms the purity of the nanoparticles. The EDS spectrum analysis indicated that the amount of $\mathrm{Zn}$ and $\mathrm{O}$ were $82.34 \%$ and $17.66 \%$, respectively, which confirms the chemical structure of $\mathrm{ZnO}$ nanoparticles.

The PL is a useful method to investigate the optical and photochemical properties of the nanoparticles. In the PL analysis, the excitation of electrons from the base energy level to the excited state is done by photons. The process of exciting electrons to a higher energy level, and then, returning them to a lower energy level is accompanied by the absorption and emission of photons. Therefore, the optical properties of $\mathrm{ZnO}$ nanoparticles were characterized by the PL spectrum at laboratory temperature $\left(25 \pm 3^{\circ} \mathrm{C}\right)$. Figure 6 shows a typical PL spectrum of $\mathrm{ZnO}$ nanoparticles. The results show that the $\mathrm{PL}$ spectra of $\mathrm{ZnO}$ nanoparticles are induced to $325 \mathrm{~nm}$ and emission peak is close to $390 \mathrm{~nm}$. In the PL spectra, there is a short wavelength region with a sharp band (390 $\mathrm{nm}$ ) located at ultraviolet region.

The visible PL emission is due to intrinsic defects such as $\mathrm{Zn}$-interstitials (Zni), O-interstitials $\left(\mathrm{O}_{\mathrm{i}}\right)$, O-vacancies $\left(\mathrm{V}_{\mathrm{O}}\right)$, Zn-vacancies $\left(\mathrm{V}_{\mathrm{Zn}}\right)$ or combinations of these single defects, which lead to an increase in the light absorption. Increasing the O-vacancies on the surface of electron-hole receptor reduces the charge carrier recombination and increases the photocatalytic process. The band gap energy of the $\mathrm{ZnO}$ nanoparticles was calculated using Eq. (15).

$\mathrm{E}=\mathrm{hc} / \lambda(15)$

Where $E, h, \lambda$, and $c$ are the band gap energy, Planck's constant, the maximum absorption of as-prepared $\mathrm{ZnO}$ nanoparticles, and light velocity, respectively. The calculated band gap of $\mathrm{ZnO}$ nanoparticles was $3.168 \mathrm{eV}$, which is shown in Figure 6 (33-35). Diffuse reflectance spectroscopy by UV-visible absorption were used for the reliance of absorbance to estimate the optical band gap of $\mathrm{ZnO}$ nanoparticles. Figure 7 shows the UV-Vis absorption spectra of the $\mathrm{ZnO}$ nanoparticles synthesized via thermal method. In the PL spectra of $\mathrm{ZnO}$ nanoparticles, a sharp absorption edge was observed at $390 \mathrm{~nm}$.

Figure 8a shows the isotherm of adsorption/desorption

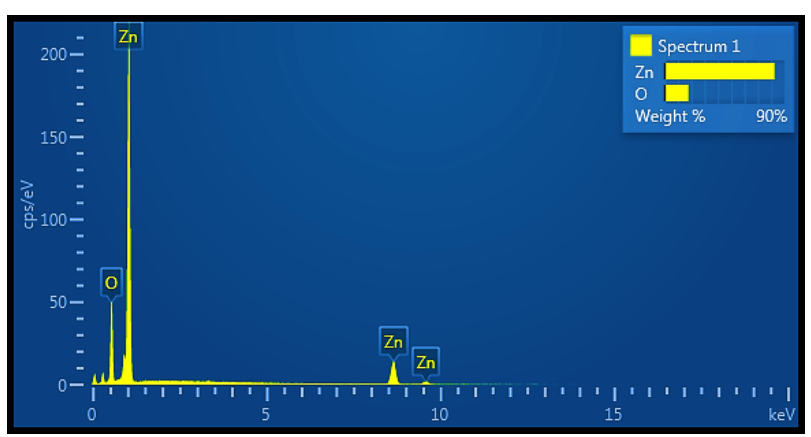

Figure 5. EDS pattern of as-prepared $\mathrm{ZnO}$ nanoparticles.

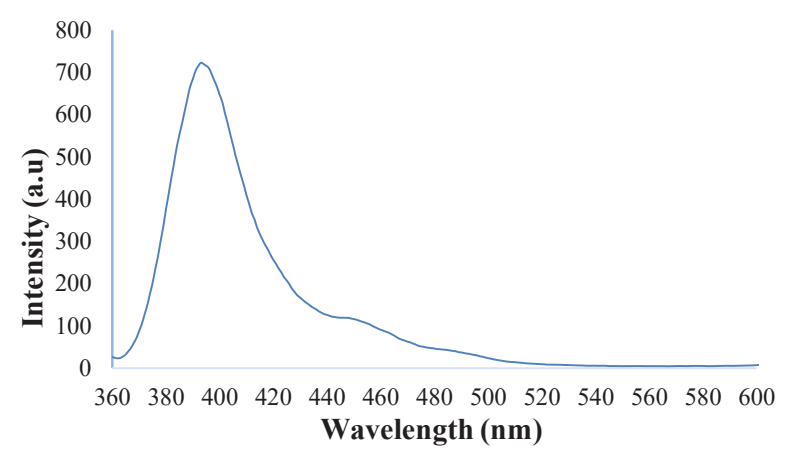

Figure 6. PL spectra of $\mathrm{ZnO}$ nanoparticles. 


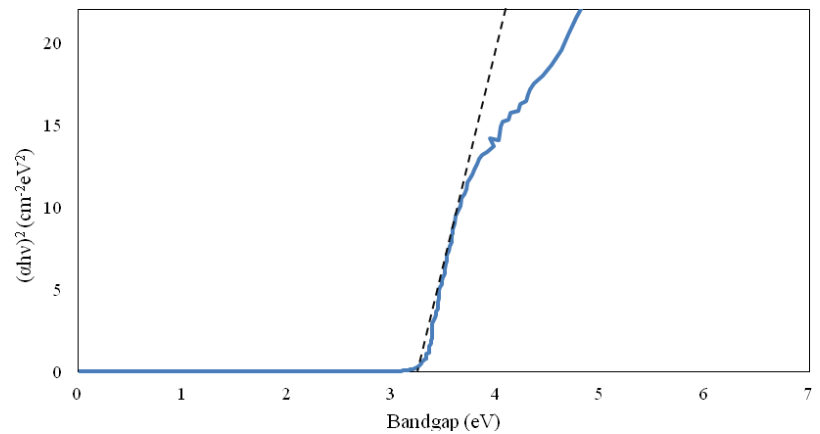

Figure 7. Optical band gap of $\mathrm{ZnO}$ synthesized.

of the $\mathrm{ZnO}$ nanoparticles synthesized. In addition, by the BET-BJH, the specific surface area of the synthesized $\mathrm{ZnO}$ nanoparticles was estimated and the results are shown in Figures $8 \mathrm{~b}$ and c. The specific surface area was obtained to be $25.504 \mathrm{~m}^{2} / \mathrm{g}$. The total pore volume and the mean pore diameter were obtained $0.078 \mathrm{~cm}^{3} / \mathrm{g}$ and $12.21 \mathrm{~nm}$, respectively.

Moreover, the beneficial role of photocatalysis is indicated in Figure 9, where the amount of metronidazole degradation by photolysis using UV-irradiation and adsorption with $\mathrm{ZnO}$ nanoparticles was compared with photocatalysis under UV-irradiation. According to Figure 9, when metronidazole solution was exposed to $\mathrm{ZnO}$, removal efficiency of $7.5 \%$ was achieved after 30 minutes, while adsorption alone does not contribute to metronidazole removal. Also, removal efficiency of metronidazole by photolysis alone was $45 \%$ after 90 minutes and increased to $95 \%$ in the presence of photocatalyst. The synergy value of removal efficiency of metronidazole was obtained $95 \%$ by the photocatalytic degradation indicating that the combination of photolysis and photocatalysis processes can degrade selected pollutants which may be attributed to the UV light with high energy that can easily penetrate to $\mathrm{ZnO}$ nanoparticles and generate more hydroxyl through mentioned reactions $(34,36,37)$.

The results of the effect of $\mathrm{pH}$ on the photocatalytic degradation rate of metronidazole at different times are shown in Figure 10. As shown in this figure, with increase of $\mathrm{pH}$ from 3 to 11 and stabilization $\mathrm{ZnO} 0.9 \mathrm{gL}^{-1}$, the removal efficiency increased from $20.32 \%$ to $95.25 \%$. Thus, $\mathrm{pH} 11$ was considered as the optimum $\mathrm{pH}$.

Figure 11 shows the changes in the absorption spectra of variations of metronidazole pending photocatalytic degradation by $\mathrm{ZnO}$ nanoparticles. The decrease in the absorption peaks of metronidazole at the maximum absorption wavelength of $320 \mathrm{~nm}$ with prolonging irradiation time indicates the degradation of metronidazole.

The efficacy of metronidazole concentration by photocatalytic degradation was evaluated at the stabilized amount of the catalyst $\left(0.9 \mathrm{gL}^{-1}\right), \mathrm{pH}=11$, and various metronidazole concentrations ( 10 to $25 \mathrm{mgL}^{-1}$ ). In Figure
12, the highest removal efficiency was obtained when the initial concentration of metronidazole was $10 \mathrm{mgL}^{-1}$.

The results of kinetic models are shown in Figure 13 and Table 2. Table 1 shows the results of pseudo-first-order kinetic at different concentrations of metronidazole.

The removal efficiency of metronidazole in the real sample under optimum conditions was obtained $72.3 \%$.

\section{Discussion}

The XRD patterns of as-prepared $\mathrm{ZnO}$ nanoparticles exhibited a crystal nature with a hexagonal (Wurtzite) structure without any impurities. Also, the average size and diameter of $\mathrm{ZnO}$ nanoparticles was obtained 54 and $2.148 \mathrm{~nm}$, respectively. Thus, $\mathrm{ZnO}$ nanoparticles have high surface area and energy. The SEM images of $\mathrm{ZnO}$ samples show that the particles density in the thermal synthesis and fixation methods are normal. Bazrafshan et al in their study in Iran investigated characteristics of ZnO by SEM, TEM, and XRD and found similar results

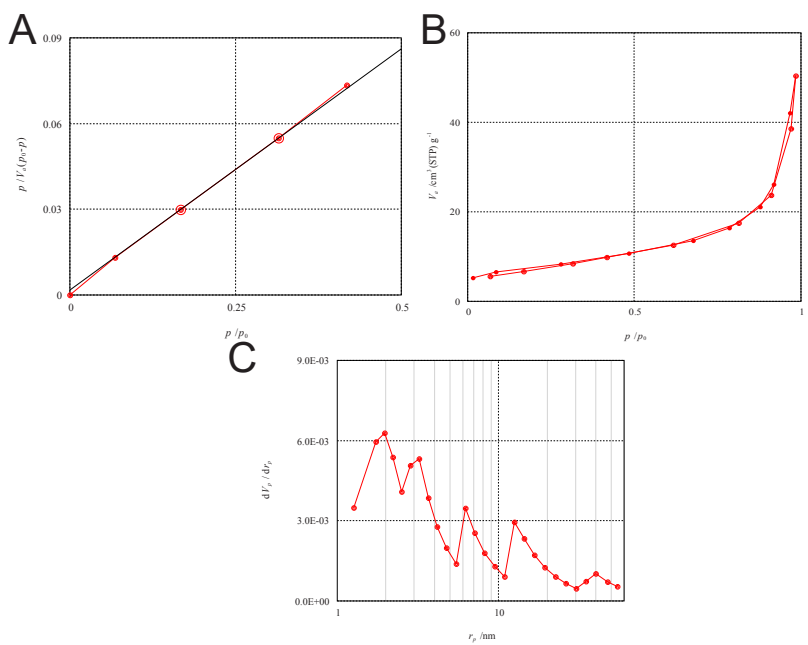

Figure 8 . (a) Adsorption/desorption isotherm, (b) BET surface area, and (c) BJH surface area of the synthesized $\mathrm{ZnO}$ nanoparticles.

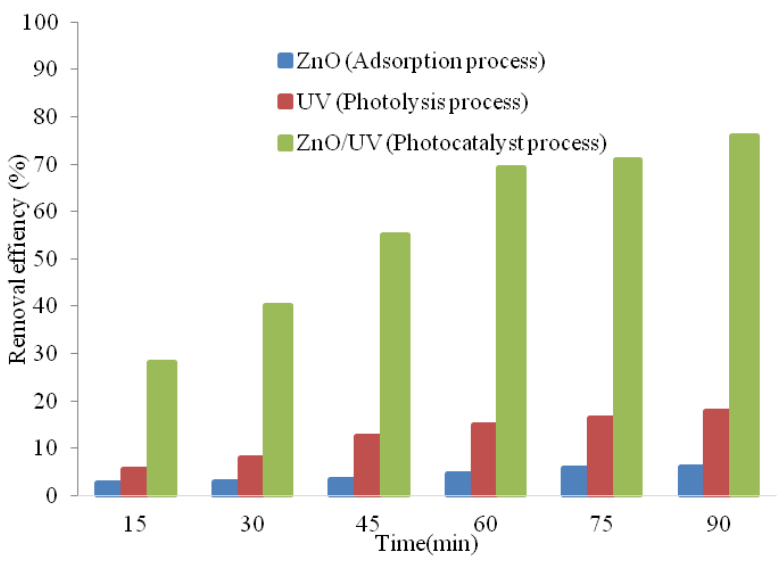

Figure 9. Metronidazole degradation and removal efficiency during UV-C, $\mathrm{ZnO}$, and UV-C-ZnO batch reactions. Reaction conditions (Metronidazole concentration: $10 \mathrm{mgL}^{-1}, \mathrm{ZnO}$ concentration: 0.9 $\mathrm{gL}^{-1}, \mathrm{pH}: 7$, reaction time: $90 \mathrm{~min}$ ). 


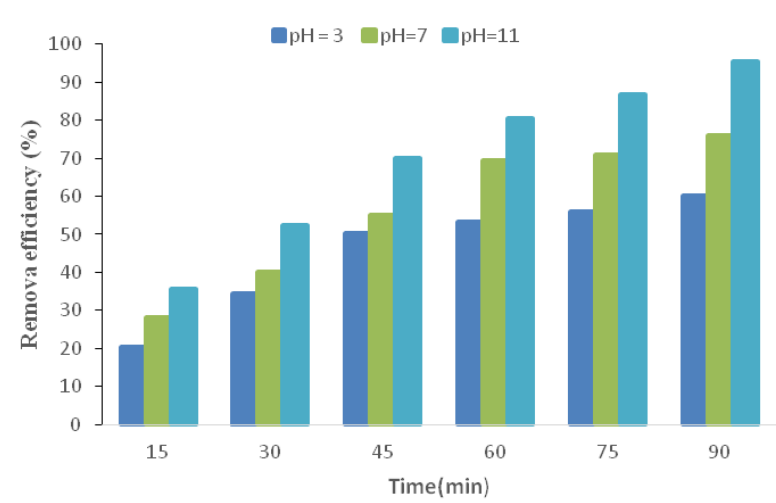

Figure 10. Variations in the removal efficiency of metronidazole vs. initial $\mathrm{pH}$ values. Initial metronidazole concentration: $10 \mathrm{mgL}^{-1}$ and contact time: $90 \mathrm{~min}$.

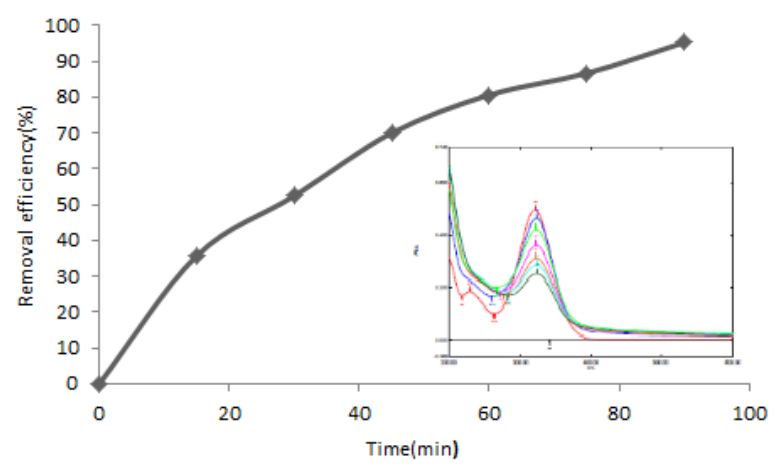

Figure 11. Changes in the UV-Vis spectra of metronidazole during photodegradation (initial metronidazole concentration:10 $\mathrm{mgL}^{-1}$; $\mathrm{pH}: 11, \mathrm{ZnO}$ concentration: $0.9 \mathrm{gL}^{-1}$ )

(38). Wang et al in their study on the synthesis of $\mathrm{ZnO}$ nanoparticles by hydrothermal synthesis method found similar results, which is consistent with the results of this study (24). In the investigation of TEM images, the small size of $\mathrm{ZnO}$ nanoparticles confirmed that a high specific surface area could show a good catalytic activity $(15,20)$. The EDS spectrum of $\mathrm{ZnO}$ nanoparticles shows four peaks, which are identified as $\mathrm{Zn}$ and $\mathrm{O}$. Therefore, pure $\mathrm{ZnO}$ nanoparticles can be prepared by thermal method. The shift of absorption peak in the visible region by visible light irradiation confirms that the $\mathrm{ZnO}$ nanoparticles synthesized in this study have a suitable photocatalytic performance under photochemical reactions.

The results show that the surface area of the synthesized nanoparticles is large, so it can intensify the photocatalytic activity of $\mathrm{ZnO}$ nanoparticles because the photocatalytic reaction occurs under UV-Vis light irradiation on the catalyst surface. The $\mathrm{pH}$ of the solution is one of the important factors in AOP such as photocatalytic degradation. The changes in the $\mathrm{pH}$ of the solution can change the surface charge of the catalyst and may change the chemical structure of the metronidazole, thus, photocatalytic processes are more dependent on $\mathrm{pH}$. The maximum removal efficiency was obtained at $\mathrm{pH} 11$.
The cause of increase of removal efficiency at this $\mathrm{pH}$ was the increased amount of $\mathrm{OH}^{-}$due to UV radiation penetration surface of catalyst, and consequently, the production of hole $\left(\mathrm{h}_{\mathrm{VB}}^{+}\right.$) reaction with $\mathrm{OH}^{-}$and formation of hydroxyl radical, which have high oxidation capability, according to Eqs. (7 and 8). At low pH, the high concentration of protons in solution prevents the formation of hydroxyl radicals $(7,8,36,39)$. Actually, the amounts of hydroxyl radicals increase by increasing the reaction time. As the degradation of metronidazole increases, the absorption peaks decreases (7). El-Kemary et al reported photocatalytic degradation of ciprofloxacin by $\mathrm{ZnO}$ nanoparticles at $\mathrm{pH} 7$, which is consistent with the results of this study (12). In photocatalytic process, $\mathrm{pH}_{\mathrm{pzc}}$ has an important role. The $\mathrm{pH}_{\mathrm{pzc}}$ of $\mathrm{ZnO}$ nanoparticle is 7.4. At a $\mathrm{pH}$ less than $\mathrm{pH}_{\mathrm{pzc}}$, the surface charge of catalyst is positive and cationic and at a $\mathrm{pH}$ more than 7.4, adsorbent is anionic and negative. At $\mathrm{pH} 11$, the concentration of $\mathrm{OH}^{-}$on the surface of catalyst increases, and according to Eq. (4), leads to the production of more hydroxyl radicals (40). The solution was placed in a dark place for $30 \mathrm{~min}$ by contact with stabilized nanoparticles as long as the surface of the nanoparticles was saturated with metronidazole

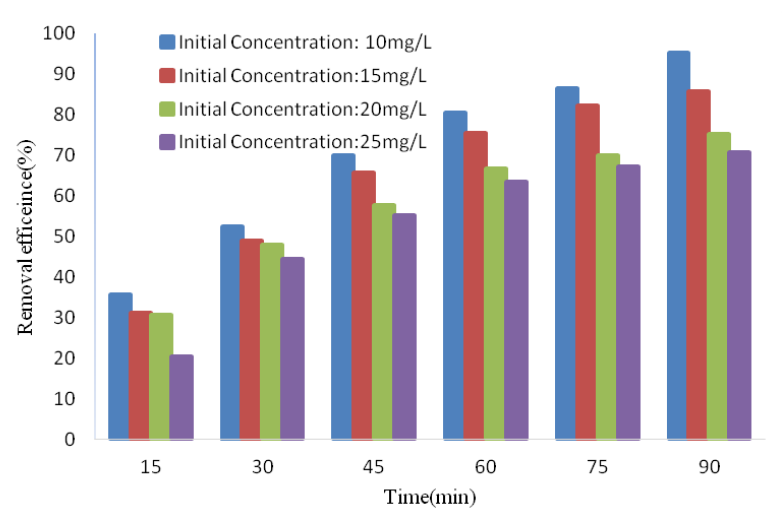

Figure 12. The effect of initial metronidazole concentration on its photocatalytic degradation. Contact time: $90 \mathrm{~min}, \mathrm{ZnO}$ concentration: $0.9 \mathrm{gL}^{-1}, \mathrm{pH}: 11$.

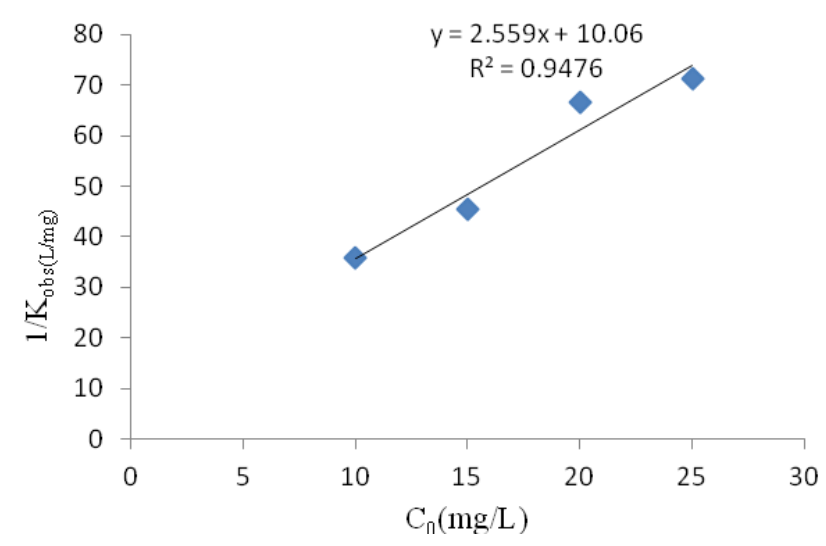

Figure 13. The dependence of the apparent first-order constant (k) of photocatalytic decomposition of metronidazole. 
Table 2. Characteristic of wastewater treatment plant sewage of Kerman

\begin{tabular}{lc}
\hline Parameter & Amount \\
\hline $\mathrm{pH}$ & 7.39 \\
\hline $\mathrm{EC}(\mu \mathrm{s} / \mathrm{m})$ & 3.4 \\
\hline TDS $\left(\mathrm{mgL}^{-1}\right)$ & 1786 \\
\hline Turbidity $(\mathrm{NTU})$ & 216 \\
\hline BOD $\left(\mathrm{mgL}^{-1}\right)$ & 278 \\
\hline $\mathrm{COD}\left(\mathrm{mgL}^{-1}\right)$ & 490
\end{tabular}

Abbreviations: BOD, biochemical oxygen demand; TDS, Total Dissolved solids; COD, chemical oxygen demand; EC, electrical conductivity

molecules and reached equilibrium (23). By increasing metronidazole concentration, the removal efficiency decreased, while by increasing the concentration of metronidazole to $25 \mathrm{mgL}^{-1}$, the removal efficiency was obtained to be $70 \%$ at a reaction time of 90 minutes. This event can be related to the catalyst amount which was kept constant, and fewer active sites that are available per substrate. Thus, generation of hydroxyl radicals on the surface of catalyst for degradation of metronidazole is limited. Also, with increasing metronidazole concentration, the radiation photons, which react with catalyst surface, are prevented and screened off, therefore, the production of hydroxyl radicals is delayed and the degradation of metronidazole is decreased (8,41-46). Sobana et al investigated photocatalytic degradation of acid red 18 by $\mathrm{ZnO}$ nanoparticles and found that by increasing the concentration of acid red 18, the removal efficiency decreased, which is consistent with the results of this study (47). According to the results, the experiment data followed pseudo-first-order kinetic and L-H models. The correlation coefficient obtained for the L-H kinetic model was 0.94 . So, the kinetic removal of metronidazole followed the L-H models. One of the most important factors in degradation process for determination of the optimum contact time is anticipation of degradation rate that is control with degradation kinetics. As shown before, the correlation coefficient $\left(\mathrm{R}^{2}\right)$ in pseudo-first-order kinetic was higher than the L-H model, so, degradation of metronidazole followed pseudo-first-order kinetic. Neghi et al showed that metronidazole degradation by photocatalyst followed pseudo-first-order kinetic (48). As the real sample had some interfering factors such as anions and cations, so, the removal efficiency was lower in the real sample than in the synthetic sample (48).

\section{Conclusion}

According to the results of the present study, thermal method was an effective and successful method for prepared $\mathrm{ZnO}$. The SEM and XRD analysis of $\mathrm{ZnO}$ showed the average size of $90 \mathrm{~nm}$. Also, TEM images present the small size of $\mathrm{ZnO}$ nanoparticles, which demonstrates the high specific surface area. The EDX shows the attendance of $\mathrm{Zn}$ and $\mathrm{O}$ in the $\mathrm{ZnO}$ nanoparticles. The PL spectra explain the suppression of recombination of the photogenerated electron hole pairs by $\mathrm{ZnO}$ nanoparticles. The efficacy of photocatalytic process using stabilized $\mathrm{ZnO}$ nanoparticles was surveyed to degrade metronidazole in aqueous solutions. The results showed high photocatalytic degradation of metronidazole at potent alkalinity conditions. Increasing the initial metronidazole concentration caused a decrease in the removal efficiency, especially at higher concentrations. Photodegradation of metronidazole follows pseudo-first-order kinetics. The results showed that photocatalytic process over stabilized $\mathrm{ZnO}$ nanoparticles have high efficiency for degradation of metronidazole in aqueous solutions.

\section{Acknowledgments}

This research was conducted in the Department of Environmental Health Engineering, Sirjan School of Medical Sciences, and sponsored by the Vice-Chancellor for Research and Technology of Kerman University of Medical Sciences. The authors would like to thank all those who supported and help them to conduct this research.

\section{Ethical issues}

The authors certify that all data collected during the study are presented in this manuscript, and no data from the study has been or will be published separately. The research was approved by the Ethics Committee of Kerman University of Medical Sciences (Ethical code: IR.KMU.REC.1397.616)

\section{Competing interests}

The authors declare that they have no conflict of interests.

\section{Authors' contributions}

All authors participated in the study design, literature search, writing the manuscript, and data collection, analysis, and interpretation. All authors critically reviewed, refined, and approved the manuscript.

\section{References}

1. Yoosefian M, Ahmadzadeh S, Aghasi M, Dolatabadi M. Optimization of electrocoagulation process for efficient removal of ciprofloxacin antibiotic using iron electrode; kinetic and isotherm studies of adsorption. Journal of Molecular Liquids 2017; 225: 544-53. doi: 10.1016/j. molliq.2016.11.093.

2. Javid N, Honarmandrad Z, Malakootian M. Ciprofloxacin removal from aqueous solutions by ozonation with calcium peroxide. Desalin Water Treat 2020; 174: 178-85. doi: 10.5004/dwt.2020.24855.

3. Nasiri A, Tamaddon F, Mosslemin MH, Faraji M. A microwave assisted method to synthesize nanoCoFe2O4@ methyl cellulose as a novel metal-organic framework for antibiotic degradation. MethodsX 2019; 6:1557-63. doi: 10.1016/j.mex.2019.06.017.

4. Malakootian M, Kannan K, Amiri Gharaghani M, Dehdarirad A, Nasiri A, Dadban Shahamat Y, et al. Removal of metronidazole from wastewater by Fe/charcoal micro electrolysis fluidized bed reactor. J Environ Chem 
Eng 2019; 7(6): 103457. doi: 10.1016/j.jece.2019.103457.

5. Bajpai S, Chand N, Mahendra M. The adsorptive removal of a cationic drug from aqueous solution using poly (methacrylic acid) hydrogels. Water SA 2014; 40(1): 49-56. doi: 10.4314/wsa.v40i1.6.

6. Prieto A, Möder M, Rodil R, Adrian L, Marco-Urrea E. Degradation of the antibiotics norfloxacin and ciprofloxacin by a white-rot fungus and identification of degradation products. Bioresour Technol 2011; 102(23): 10987-95. doi: 10.1016/j.biortech.2011.08.055.

7. Yuan F, Hu C, Hu X, Qu J, Yang M. Degradation of selected pharmaceuticals in aqueous solution with UV and UV/ H2O2. Water Res 2009; 43(6): 1766-74. doi: 10.1016/j. watres.2009.01.008.

8. Darvishi Cheshmeh Soltani R, Rezaee A, Safari M, Khataee AR, Karimi B. Photocatalytic degradation of formaldehyde in aqueous solution using $\mathrm{ZnO}$ nanoparticles immobilized on glass plates. Desalin Water Treat 2015; 53(6): 1613-20. doi: 10.1080/19443994.2013.855674.

9. Malakootian M, Nasiri A, Amiri Gharaghani M. Photocatalytic degradation of ciprofloxacin antibiotic by $\mathrm{TiO} 2$ nanoparticles immobilized on a glass plate. Chemical Engineering Communications 2020; 207(1): 56-72. doi: 10.1080/00986445.2019.1573168.

10. Sharifpour H, Javid N, Malakootian M. Investigation of single-walled carbon nanotubes in removal of Penicillin G (Benzyl penicillin sodium) from aqueous environments. Desalin Water Treat 2018; 124: 248-55. doi: 10.5004/ dwt.2018.22726.

11. Lim TH, Kim SD. Photocatalytic degradation of trichloroethylene over $\mathrm{TiO} 2 / \mathrm{SiO} 2$ in an annulus fluidized bed reactor. Korean J Chem Eng 2002; 19(6): 1072-7. doi: 10.1007/BF02707235.

12. El-Kemary M, El-Shamy H, El-Mehasseb I. Photocatalytic degradation of ciprofloxacin drug in water using $\mathrm{ZnO}$ nanoparticles. Journal of Luminescence 2010; 130(12): 2327-31. doi: 10.1016/j.jlumin.2010.07.013.

13. Tamaddon F, Nasiri A, Yazdanpanah G. Photocatalytic degradation of ciprofloxacin using CuFe2O4@methyl cellulose based magnetic nanobiocomposite. MethodsX 2020; 7: 74-81. doi: 10.1016/j.mex.2019.12.005.

14. Srivastava V, Gusain D, Sharma YC. Synthesis, characterization and application of zinc oxide nanoparticles (n-ZnO). Ceramics International 2013; 39(8): 9803-8. doi: 10.1016/j.ceramint.2013.04.110.

15. Lu M, Hou H, Wei C, Guan X, Wei W, Wang GS. Preparation of Quasi-MIL-101 (Cr) loaded ceria catalysts for the selective catalytic reduction of NOx at Low temperature. catalysts 2020; 10(1): 140. doi: 10.3390/catal10010140.

16. Duan Y, Shen Y. Synthesis of $\mathrm{ZnO}-\mathrm{CuO} / \mathrm{MCM}-48$ photocatalyst for the degradation of organic pollutions. Water Sci Technol 2017; 76(1-2): 172-81. doi: 10.2166/ wst.2017.196.

17. Khan SA, Noreen F, Kanwal S, Iqbal A, Hussain G. Green synthesis of $\mathrm{ZnO}$ and $\mathrm{Cu}$-doped $\mathrm{ZnO}$ nanoparticles from leaf extracts of Abutilon indicum, Clerodendrum infortunatum, Clerodendrum inerme and investigation of their biological and photocatalytic activities. Materials Science and Engineering: C 2018; 82: 46-59. doi: 10.1016/j. msec.2017.08.071.
18. Maleki A, Safari M, Rezaee R, Darvishi Cheshmeh Soltani R, Shahmoradi B, Zandsalimi Y. Photocatalytic degradation of humic substances in the presence of $\mathrm{ZnO}$ nanoparticles immobilized on glass plates under ultraviolet irradiation. Sep Sci Technol 2016; 51(14): 2484-9. doi: 10.1080/01496395.2016.1213746.

19. Serrà A, Zhang Y, Sepúlveda B, Gómez E, Nogués J, Michler J, et al. Highly reduced ecotoxicity of ZnO-based micro/ nanostructures on aquatic biota: Influence of architecture, chemical composition, fixation, and photocatalytic efficiency. Water Research 2020; 169: 115210. doi: 10.1016/j. watres.2019.115210.

20. Nakhaei Pour M, Rangkooy HA, Jahani F, Golbaghi A, Shojaee- Farah Abady H, Nematpour L. Removal of styrene by the synthesized $\mathrm{ZnO}$ nanoparticles coated on the activated carbon adsorbent in the presence of UV irradiation. Environmental Health Engineering and Management Journal. 2019;6(4):225-32.Doi: 10.15171/ EHEM.2019.25

21. Paul T, Dodd MC, Strathmann TJ. Photolytic and photocatalytic decomposition of aqueous ciprofloxacin: transformation products and residual antibacterial activity. Water Research 2010; 44(10): 3121-32. doi: 10.1016/j. watres.2010.03.002.

22. Liu J, Wang Y, Ma J, Peng Y, Wang A. A review on bidirectional analogies between the photocatalysis and antibacterial properties of ZnO. J Alloys Compd 2019; 783: 898-918. doi: 10.1016/j.jallcom.2018.12.330.

23. Vaiano V, Iervolino G. Facile method to immobilize $\mathrm{ZnO}$ particles on glass spheres for the photocatalytic treatment of tannery wastewater. J Colloid Interface Sci 2018; 518: 192-9. doi: 10.1016/j.jcis.2018.02.033.

24. Wang H, Xie J, Yan K, Duan M. Growth mechanism of different morphologies of $\mathrm{ZnO}$ crystals prepared by hydrothermal method. Journal of Materials Science \& Technology 2011; 27(2): 153-8. doi: 10.1016/S10050302(11)60041-8.

25. Khataee A, Pons M-N, Zahraa O. Photocatalytic degradation of three azo dyes using immobilized $\mathrm{TiO} 2$ nanoparticles on glass plates activated by UV light irradiation: Influence of dye molecular structure. J Hazard Mater 2009;168(1):451-7. https://doi.org/10.1016/j.jhazmat.2009.02.052

26. Fathinia M, Khataee A, Zarei M, Aber S. Comparative photocatalytic degradation of two dyes on immobilized TiO2 nanoparticles: Effect of dye molecular structure and response surface approach. Journal of Molecular Catalysis A: Chemical 2010; 333(1-2): 73-84. doi: 10.1016/j. molcata.2010.09.018.

27. Nasiri A, Tamaddon F, Mosslemin MH, Amiri Gharaghani M, Asadipour A. Magnetic nano-biocomposite CuFe2O4@ methylcellulose (MC) prepared as a new nano-photocatalyst for degradation of ciprofloxacin from aqueous solution. Environ Health Eng Manag 2019; 6(1): 41-51. doi: 10.15171/ EHEM.2019.05.

28. Malakootian M, Nasiri A, Asadipour A, Faraji M, Kargar E. A facile and green method for synthesis of $\mathrm{ZnFe} 2 \mathrm{O} 4 @ \mathrm{CMC}$ as a new magnetic nanophotocatalyst for ciprofloxacin removal from aqueous media. MethodsX 2019; 6: 1575-80. doi: 10.1016/j.mex.2019.06.018.

29. Khataee A, Kuranşan M, Karaca S, Sheydaei M. 
Photocatalytic ozonation of metronidazole by synthesized zinc oxide nanoparticles immobilized on montmorillonite. J Taiwan Inst Chem Eng 2017; 74: 196-204. doi: 10.1016/j. jtice.2017.02.014.

30. Malakootian $M$, Mahdizadeh $H$, Khavari M, Nasiri A, Amiri Gharaghani M, Khatami $M$, et al. Efficiency of novel $\mathrm{Fe} / \mathrm{charcoal} /$ ultrasonic micro-electrolysis strategy in the removal of Acid Red 18 from aqueous solutions. J Environ Chem Eng 2020; 8(2): 103553. doi: 10.1016/j. jece.2019.103553.

31. Malakootian M, Smith J, Amiri Gharaghani M, Mahdizadeh H, Nasiri A, Yazdanpanah G. Decoloration of textile Acid Red 18 dye by hybrid UV/COP advanced oxidation process using $\mathrm{ZnO}$ as a catalyst immobilized on a stone surface. Desalin Water Treat 2020; 182: 385-94. doi: 10.5004/ dwt.2020.25216.

32. Mahdizadeh H, Nasiri A, Gharaghani MA, Yazdanpanah G. Hybrid UV/COP advanced oxidation process using $\mathrm{ZnO}$ as a catalyst immobilized on a stone surface for degradation of acid red 18 dye. MethodsX 2020; 7: 101118. doi: 10.1016/j. mex.2020.101118

33. Bhatia S, Verma N. Photocatalytic activity of $\mathrm{ZnO}$ nanoparticles with optimization of defects. Mater Res Bull 2017; 95: 468-76. doi: 10.1016/j.materresbull.2017.08.019.

34. Amiri Gharaghani M, Malakootian M. Photocatalytic degradation of the antibiotic ciprofloxacin by $\mathrm{ZnO}$ nanoparticles immobilized on a glass plate. Desalin Water Treat 2017; 89: 304-14. doi: 10.5004/dwt.2017.21378.

35. Chen X, Mao SS. Titanium dioxide nanomaterials: Synthesis, properties, modifications, and applications. Chem Rev 2007; 107(7): 2891-959. doi: 10.1021/cr0500535.

36. Odling G, Pong ZY, Gilfillan G, Pulham CR, Robertson $\mathrm{N}$. Bismuth titanate modified and immobilized $\mathrm{TiO} 2$ photocatalysts for water purification: broad pollutant scope, ease of re-use and mechanistic studies. Environ Sci 2018; 4(12): 2170-8. doi: 10.1039/c8ew00568k.

37. Latha P, Karuthapandian S. Novel, Facile and Swift Technique for synthesis of $\mathrm{CeO} 2$ nanocubes immobilized on zeolite for removal of CR and MO dye. J Clust Sci 2017; 28: 3265-80. doi: 10.1007/s10876-017-1292-z.

38. Bazrafshan E, Al-Musawi TJ, Silva MF, Panahi AH, Havangi M, Mostafapur FK. Photocatalytic degradation of catechol using $\mathrm{ZnO}$ nanoparticles as catalyst: Optimizing the experimental parameters using the Box-Behnken statistical methodology and kinetic studies. Microchemical Journal 2019; 147: 643-53. doi: 10.1016/j.microc.2019.03.078.

39. Malakootian M, Nasiri A, Alibeigi AN, Mahdizadeh $\mathrm{H}$, Gharaghani MA. Synthesis and stabilization of $\mathrm{ZnO}$ nanoparticles on a glass plate to study the removal efficiency of acid red 18 by hybrid advanced oxidation process (Ultraviolet/ZnO/ultrasonic). Desalin Water Treat
2019; 170: 325-36. doi: 10.5004/dwt.2019.24728.

40. Selvam K, Muruganandham M, Muthuvel I, Swaminathan $M$. The influence of inorganic oxidants and metal ions on semiconductor sensitized photodegradation of 4-fluorophenol. Chemical Engineering Journal 2007; 128(1): 51-7. doi: 10.1016/j.cej.2006.07.016.

41. Min OM, Ho LN, Ong SA, Wong YS. Comparison between the photocatalytic degradation of single and binary azo dyes in $\mathrm{TiO} 2$ suspensions under solar light irradiation. Journal of Water Reuse and Desalination 2015; 5(4): 579-91. doi: 10.2166/wrd.2015.022.

42. Mou H, Song C, Zhou Y, Zhang B, Wang D. Design and synthesis of porous $\mathrm{Ag} / \mathrm{ZnO}$ nanosheets assemblies as super photocatalysts for enhanced visible-light degradation of 4-nitrophenol and hydrogen evolution. Applied Catalysis B: Environmental 2018; 221: 565-73. doi: 10.1016/j. apcatb.2017.09.061.

43. Ong CB, Ng LY, Mohammad AW. A review of $\mathrm{ZnO}$ nanoparticles as solar photocatalysts: synthesis, mechanisms and applications. Renewable and Sustainable Energy Reviews 2018; 81(Part 1): 536-51. doi: 10.1016/j. rser.2017.08.020

44. Tamaddon F, Mosslemin MH, Asadipour A, Gharaghani MA, Nasiri A. Microwave-assisted preparation of ZnFe2O4@ methyl cellulose as a new nano-biomagnetic photocatalyst for photodegradation of metronidazole. Int J Biol Macromol 2020; 154: 1036-49. doi: 10.1016/j. ijbiomac.2020.03.069.

45. Ebrahimi A, Jafari N, Ebrahimpour K, Nikoonahad A, Mohammadi A, Fanaei F, et al. The performance of TiO2/ NaY-zeolite nanocomposite in photocatalytic degradation of Microcystin-LR from aqueous solutions: Optimization by response surface methodology (RSM). Environmental Health Engineering And Management Journal. 2020:7(4):245-256. https:10.34172/EHEM.2020.29

46. Rangkooy HA, Jahani F, Siahi Ahangar A. Photocatalytic removal of xylene as a pollutant in the air using $\mathrm{ZnO}$ activated carbon, $\mathrm{TiO} 2$-activated carbon, and $\mathrm{TiO} 2 / \mathrm{ZnO}$ activated carbon nanocomposites. Environmental Health Engineering and Management Journal. 2020;7(1):41-7.doi: 10.34172/EHEM.2020.06.

47. Sobana N, Swaminathan M. The effect of operational parameters on the photocatalytic degradation of acid red 18 by ZnO. Separation and Purification Technology 2007; 56(1): 101-7. doi: 10.1016/j.seppur.2007.01.032.

48. Neghi N, Kumar M, Burkhalov D. Synthesis and application of stable, reusable $\mathrm{TiO} 2$ polymeric composites for photocatalytic removal of metronidazole: Removal kinetics and density functional analysis. Chem Eng J. 2019;359:96375. doi: 10.1016/j.cej.2018.11.090 